\title{
Toxocara (Nematoda: Ascaridida) and Other Soil-Transmitted Helminth Eggs Contaminating Soils in Selected Urban and Rural Areas in the Philippines
}

\author{
Vachel Gay V. Paller and Emmanuel Ryan C. de Chavez \\ Animal Biology Division, Institute of Biological Sciences, University of the Philippines Los Baňos, 4030 Laguna, Philippines \\ Correspondence should be addressed to Vachel Gay V. Paller; vvpaller@up.edu.ph
}

Received 2 July 2014; Accepted 10 September 2014; Published 14 October 2014

Academic Editor: Lihua Xiao

Copyright (C) 2014 V. G. V. Paller and E. R. C. de Chavez. This is an open access article distributed under the Creative Commons Attribution License, which permits unrestricted use, distribution, and reproduction in any medium, provided the original work is properly cited.

\begin{abstract}
The extent of contamination of soils with soil transmitted helminthes (STH) eggs, particularly Toxocara, was determined in selected urban and rural towns of Laguna, Philippines. Soil samples were collected from public schools, house yards, and empty lots. Results revealed that, of the 1480 soil samples collected, 460 (31\%) were positive for STH eggs. Toxocara sp. was the most prevalent (77\%), followed by Ascaris sp. (11\%), hookworms/strongyles/free-living nematodes (7\%), and Trichuris sp. (5\%). Some soil physicochemical parameters were also determined and associated with Toxocara eggs prevalence and density in soil. Results revealed that Toxocara sp. eggs were most prevalent in less acidic, relatively high temperature and high moisture soil conditions. They were also prevalent in sandy, silty, and loamy soil textures but less prevalent in clayey. No significant differences were found between depth $1(0-5 \mathrm{~cm})$ and depth $2(6-10 \mathrm{~cm})$. This study revealed that Toxocara sp. eggs are ubiquitous and the extent of contamination in soils from the selected towns of Laguna is relatively high. Hence, the data generated in this study can be used in promoting public awareness, particularly for pet owners and local health officials, for effective prevention and control of this parasitosis.
\end{abstract}

\section{Introduction}

Soil is a potential source of human diseases caused by many helminth parasites. Based on the report of the World Health Organization (WHO), last century two billions of the world populations are infected by soil-transmitted helminthes (STH) such as Ascaris lumbricoides, hookworms, and Trichuris trichiura. These parasites commonly cause infections and diseases of chronic morbidity and debilitation [1]. However, Toxocara sp. is a little-known parasite but is reported to be an emerging STH parasitic infectious agent.

Toxocariasis is a zoonotic disease caused by the larva of Toxocara canis and T. cati from dogs and cats, respectively. Humans are commonly infected by ingestion of embryonated eggs from the soil or through contaminated hands and fomites. Before becoming infective, the ova undergo further development in the soil and can be viable for several years.
Children are the most vulnerable ones because of their habit of playing with soil or objects contaminated with eggs [2]. Toxocara causes visceral larval migrans characterized by migration of larvae to different organs including the eyes and brain. It can cause stunted growth, decreased physical activity, and poor physical and mental development in children. Moreover, toxocariasis accounts for preventable childhood illnesses and blindness associated with poor hygiene [3].

There is already an evidence of Toxocara infection among public school children in Los Baños, Philippines [4]. Through ELISA test, the study reported $43 \%$ seroprevalence of Toxocara sp. infection among public school children. Soil contamination by parasite eggs was also reported recently in the Philippines but only on a small scale in a small village [5]. No studies have been conducted on a larger scale regarding the extent of Toxocara sp. eggs contaminating the soil even though feral dogs and cats abound in the country. 
Furthermore, current understanding of the health impact of toxocariasis is poor due to insufficient public awareness and lack of interventions of local health units.

Thus, in this research, the extent of soil contamination by Toxocara eggs in selected school grounds, house yards, and playgrounds in the four municipalities of Laguna, namely, Los Baños, Bay, Calauan, and Calamba, was investigated. In addition, some physicochemical parameters of soils were determined and correlated with prevalence and density of Toxocara sp. eggs. Hence, this study aimed to provide information on the extent of STH contamination in selected towns of Laguna, Philippines, and to ascertain the relationship between prevalence rates with some soil characteristics. The data generated in this study can be used in promoting public awareness to prevent contamination of soils and prevent children from becoming infected with soil-borne parasites.

\section{Methodology}

2.1. Collection Sites and Sampling Design. The survey was carried out for a period of two years in the towns of Bay, Los Baños, Calamba, and Calauan, Laguna. The villages from the selected towns were randomly selected from which school grounds, house yards, and empty lots were identified. Thirty soil samples from each chosen house yard and empty lot were collected and 20 for school grounds. Empty lots referred to here were abandoned lots that may be frequented by feral animals and children as playground, while sampling sites for school grounds included classroom premises, playground, and gardens. Approximately $200 \mathrm{~g}$ soil samples were taken at two different depths: depth 1 at $0-5 \mathrm{~cm}$ and depth 2 at 6$10 \mathrm{~cm}$. The soil samples were placed and sealed in polyethylene bags prior to laboratory analysis. Soil texture (e.g., sandy, clayey, silty, or loamy), $\mathrm{pH}$, temperature, and moisture content were determined following standard procedures.

2.2. Soil Processing for Isolation and Identification of SoilTransmitted Helminth Eggs. The soil samples were air-dried overnight and strained in a $125 \mu \mathrm{m}$ sieve until $2 \mathrm{~g}$ of sample filtrate was obtained. The two-gram sample obtained was placed in a calibrated tube and then washed with $0.5 \%$ Tween solution. Modified sucrose floatation technique was employed to harvest the eggs from the soil samples [6]. Briefly, $2 \mathrm{~g}$ soil sample was washed with $0.5 \%$ Tween solution; then the filtrate was washed again with $6 \mathrm{~mL}$ distilled water. The suspension was mixed using a mechanical mixer and then centrifuged for 10 minutes at $1800 \mathrm{rpm}$. After centrifugation, the supernatant was decanted from the tube; then the sediment was mixed with $8 \mathrm{~mL}$ of 1.2 specific gravity sucrose solution. The suspension was again mixed thoroughly with a mixer, lifting the bottom to avoid build-up. The tube was centrifuged again for 10 minutes at $1800 \mathrm{rpm}$. After centrifugation, 1.3 specific gravity of sucrose solution was slowly added into the tube, using a $10 \mathrm{~mL}$ syringe, up to the brim. A cover slip was placed on the mouth of the calibrated tube to collect the topmost portion of the sucrose suspension. After which, the cover slip was placed on top of a glass slide with proper label. The slides were observed for presence of
STH eggs using compound light microscope at 100x and 400x magnification. The size of the specimens was determined using an ocular micrometer.

2.3. Soil Physicochemical Parameters. In obtaining the temperature of the soil sample, a mercury thermometer was placed inside a $5 \mathrm{~cm}$ hole for 2 minutes in each collection site. Soil $\mathrm{pH}$ was obtained using a $\mathrm{pH}$ meter that was placed in a soil-water ( $2 \mathrm{~g}: 1 \mathrm{~mL})$ paste for 2 minutes [7]. On the other hand, soil moisture content was determined by gravimetric method using the formula

$$
\text { Moisture content }=\frac{w_{\circ}-w_{1}}{w_{\circ}} \times 100,
$$

where $w_{\circ}$ is the predried weight of the sample $(100 \mathrm{~g})$ and $w_{1}$ is the weight after the sample was oven-dried for 24 hours at $125^{\circ} \mathrm{C}$.

Lastly, the soil texture (sandy, loamy, clayey, and silty) was estimated following Lesikar method [8]. Briefly, water was added to the soil at $1 \mathrm{~mL}: 2 \mathrm{~g}$ proportion. Then the soil was kneaded until bolus was formed.

2.4. Data Analysis. Chi-square test was used, at $\alpha=0.05$, for the comparison of prevalence. For the comparison of density of eggs among the soil samples from different locations and among soil textures Kruskal-Wallis $H$ test was used. For the comparison of mean intensities of eggs between depths, Mann-Whitney $U$ Test was used. Relationship between contamination rates and soil physicochemical properties was analyzed using Pearson's correlation analysis.

\section{Results}

Studies on soil-transmitted helminth (STH) mostly focused on the extent of its infection in humans, particularly among children. However, STH eggs are first released and incubated in soil before infecting the hosts. Hence, soil is considered as the greatest source of STH infection. However, there are relatively few studies in the Philippines conducted to determine the extent of STH eggs contamination in soil, particularly Toxocara sp. eggs.

The present study revealed that, of the 1480 samples collected, 460 (31\%) were found positive for STH eggs. Toxocara showed the highest prevalence rate of $77 \%$, followed by Ascaris (11\%), hookworms/strongyles/free-living nematodes (7\%), and Trichuris (5\%) (Figure 1). The eggs and/or larvae of hookworms, strongyles, and free-living nonparasitic nematodes were grouped together as they were difficult to distinguish from one another. Meanwhile, only Toxocara prevalence and density in soil were considered in the study for comparison among various sampling sites since it showed a remarkably high prevalence. The prevalence rate for Toxocara eggs in Bay, Calauan, Los Baños, and Calamba was 28\%, 26\%, $33 \%$, and $38 \%$, respectively. The prevalence of Toxocara eggs in Calamba and Los Baños (urban) was relatively higher than in Calauan and Bay (rural). However, the difference was not significantly different among them $\left(X^{2}=1.503\right.$, d.f. $=3$, 


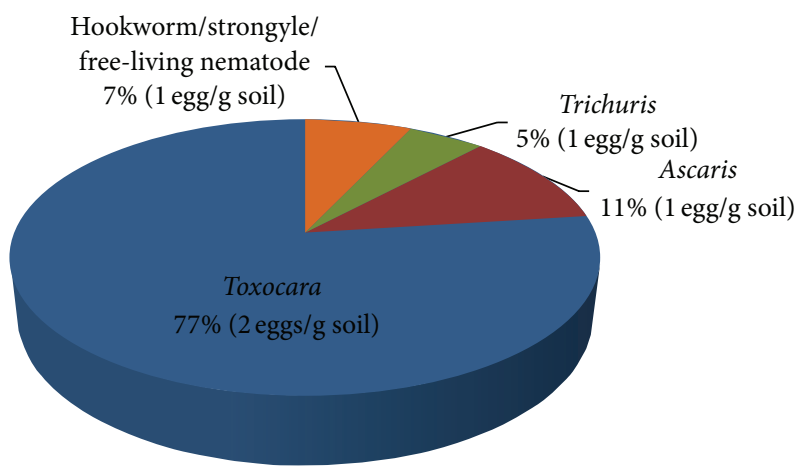

FIGURE 1: Prevalence (\%) and mean density of soil-transmitted helminth (STH) eggs collected from soils in selected towns of Laguna, Philippines.

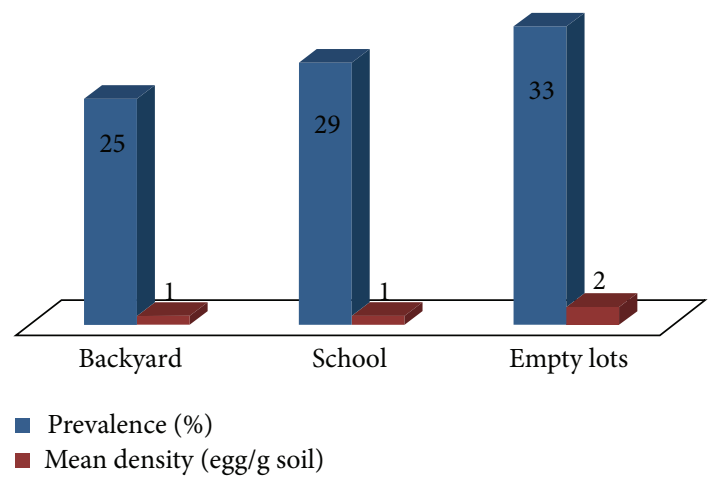

FIgURE 2: Prevalence and mean density of Toxocara eggs in soils from various sampling sites of selected towns in Laguna, Philippines.

$P=0.373)$. The mean egg density for Calamba was 2 eggs $/ g$ soil and $1 \mathrm{egg} / \mathrm{g}$ soil for the three towns.

On the other hand, assessment of the prevalence and mean density of Toxocara egg contamination in soils from schools, empty lots, and house yards was also done in the study (Figure 2). Samples were obtained from these specific locations where children usually visit to play. Results showed that Toxocara eggs were more prevalent in empty lots (33\%) followed by schools (29\%) and backyards (25\%). However, prevalence among the various sampling sites was not significantly different $\left(X^{2}=1.627\right.$, d.f. $\left.=2, P=0.546\right)$. The mean egg density for empty lots was 2 eggs/g soil while the rest had 1 egg/g soil.

Development of STH eggs in the outside environment, particularly in soil, is affected by several factors such as temperature, humidity, $\mathrm{pH}$, depth, and soil texture [9-12]. These might affect their development by hastening their embryonation, viability, infectivity, and size. Hence, the correlation between soil physicochemical factors such as soil texture, temperature, moisture content, $\mathrm{pH}$, and depth on the prevalence and mean density of Toxocara eggs was also assessed in this study. Figure 3 shows the prevalence of Toxocara eggs among different soil textures. It was observed that sandy soils had the highest prevalence (38\%), followed by loamy (32\%), silty (30\%), and clayey soil (18\%). However,

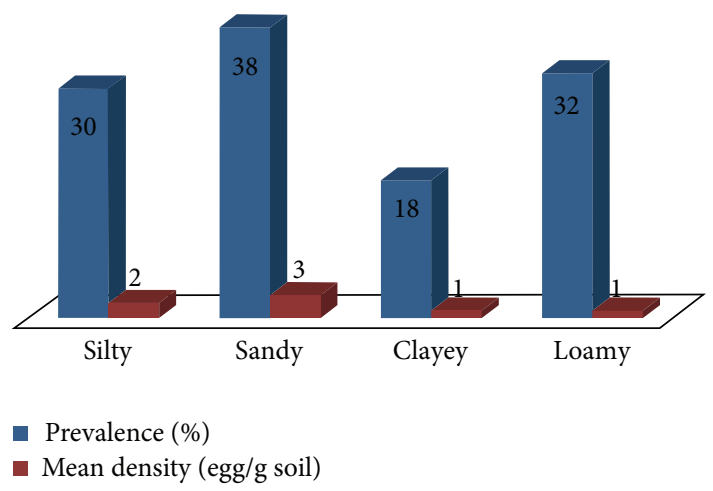

Figure 3: Prevalence and mean density of Toxocara eggs in different soil textures from selected towns in Laguna, Philippines.

TABLE 1: Some physicochemical characteristics of soils from selected towns in Laguna, Philippines.

\begin{tabular}{lccc}
\hline Municipality & & Mean & \\
& Temperature $\left({ }^{\circ} \mathrm{C}\right)$ & $\mathrm{pH}$ & Moisture $(\%)$ \\
\hline Bay & & & \\
San Isidro & $30.0 \pm 0.00$ & $6.8 \pm 0.43$ & $15.30 \pm 0.60$ \\
Tagumpay & $28.5 \pm 0.38$ & $6.8 \pm 0.58$ & $5.30 \pm 7.88$ \\
Tranca & $28.9 \pm 1.23$ & $6.6 \pm 0.29$ & $20.0 \pm 11.05$ \\
Calauan & & & \\
Perez & $30.14 \pm 0.69$ & $7.2 \pm 0.24$ & $82.2 \pm 5.313$ \\
Lamot II & $26.86 \pm 1.07$ & $7.5 \pm 0.18$ & $82.5 \pm 4.76$ \\
Imok & $27.14 \pm 1.07$ & $7.4 \pm 0.24$ & $77.5 \pm 3.85$ \\
Los Baños & & & \\
Bambang & $27.9 \pm 1.86$ & $7.1 \pm 0.38$ & $12.2 \pm 7.64$ \\
Batong Malake & $30.5 \pm 2.31$ & $7.1 \pm 0.47$ & $18.0 \pm 10.01$ \\
Bayog & $28.0 \pm 0.81$ & $7.5 \pm 0.40$ & $13.5 \pm 9.27$ \\
Maahas & $27.4 \pm 0.94$ & $7.4 \pm 0.41$ & $10.2 \pm 8.40$ \\
Mayondon & $28.9 \pm 1.07$ & $6.3 \pm 0.69$ & $14.8 \pm 8.47$ \\
Calamba & & & \\
Lecheria & $30.3 \pm 2.19$ & $7.2 \pm 0.28$ & $15.9 \pm 6.70$ \\
Looc & $34.3 \pm 4.79$ & $7.3 \pm 0.18$ & $11.4 \pm 8.10$ \\
Uwisan & $35.0 \pm 2.53$ & $7.4 \pm 0.39$ & $13.9 \pm 6.39$ \\
Singko & $31.0 \pm 3.45$ & $7.2 \pm 0.30$ & $12.5 \pm 7.02$ \\
La Mesa & $33.8 \pm 2.89$ & $7.3 \pm 0.32$ & $15.6 \pm 6.71$ \\
Bucal & $31.1 \pm 4.05$ & $7.3 \pm 0.27$ & $15.0 \pm 6.98$ \\
\hline
\end{tabular}

there was no statistical difference between the prevalence of eggs in different soil textures $\left(X^{2}=1.736 ; P=0.359\right)$. In terms of density, sandy soil also harbored the most number of STH eggs (3 eggs/g soil) while clayey soil had the least (1 egg/g soil). Table 1 shows the mean temperature, moisture content, and $\mathrm{pH}$ of the soils from each village in the four towns of Laguna, while Table 2 shows the correlation coefficient $(r)$ values to determine the relationship of the environmental factors on the prevalence and mean density of eggs. Results revealed positive correlations between prevalence and mean density with all the physicochemical factors mentioned above. There is a positive correlation $(r=0.680 ; P=0.152)$ between temperature and the density of eggs in soils, but 
TABLE 2: Correlation coefficient $(r)$ of the prevalence and density of STH eggs with some physicochemical parameters of soils from selected towns in Laguna, Philippines.

\begin{tabular}{lccc}
\hline Municipality & Temperature $\left({ }^{\circ} \mathrm{C}\right)$ & $\mathrm{pH}$ & Moisture (\%) \\
\hline Bay & 0.204 & 0.500 & 0.966 \\
Prevalence & 0.706 & 0.950 & 0.500 \\
Density & & & \\
Calauan & & & \\
Prevalence & 0.495 & 0.700 & 0.546 \\
Density & 0.565 & 0.756 & 0.799 \\
Los Baños & & & \\
Prevalence & -0.485 & 0.742 & 0.574 \\
Density & 0.522 & 0.380 & 0.676 \\
Calamba & & & \\
Prevalence & 0.196 & -0.674 & 0.326 \\
Density & 0.475 & 0.239 & 0.215 \\
All sites & & & \\
Prevalence & $\mathbf{0 . 3 4 3}$ & $\mathbf{0 . 5 6 7}$ & $\mathbf{0 . 7 9 9}$ \\
Density & $\mathbf{0 . 6 8 0}$ & $\mathbf{0 . 4 3 1}$ & $\mathbf{0 . 6 2 7}$ \\
P value & & & \\
Prevalence & $\mathbf{0 . 4 0 5}$ & $\mathbf{0 . 1 4 3}$ & $\mathbf{0 . 0 2 7}$ \\
Density & $\mathbf{0 . 1 5 2}$ & $\mathbf{0 . 5 6 0}$ & $\mathbf{0 . 0 3 8}$ \\
\hline
\end{tabular}

${ }^{*}$ Significant at $P<0.05$.

a weak positive correlation with prevalence $(r=0.343$; $P=0.405$ ), although both are not statistically significant. There is also a significant strong positive correlation between prevalence and moisture content $(r=0.799 ; P=0.027)$ and with parasite density $(r=0.627 ; P=0.038)$. On the other hand, $\mathrm{pH}$ showed also a positive but moderate correlation with prevalence $(r=0.567 ; P=0.143)$ and density of Toxocara eggs $(r=0.430 ; P=0.560)$, although statistically not significant.

Meanwhile, depth $1(0-5 \mathrm{~cm})$ and depth $2(6-10 \mathrm{~cm})$ showed prevalence of $38 \%$ and $34 \%$, respectively; however, there was no significant difference between the two depths $(U=1.361$, d.f. $=1, P=0.249)$. The mean density for both depths was $1 \mathrm{egg} / \mathrm{g}$ soil. Depth 1 at $0-5 \mathrm{~cm}$ depth showed higher Toxocara eggs prevalence (38\%) than depth 2 at 6$10 \mathrm{~cm}$ depth (34\%) (Figure 4); however, this was not significant $\left(X^{2}=7716 ; P=0.352\right)$. In addition, the mean densities of STH eggs between depth $1(0-5 \mathrm{~cm})$ and depth $2(6-10 \mathrm{~cm})$ were both $1 \mathrm{egg} / \mathrm{g}$ soil.

\section{Discussion}

Dogs and cats are the definitive hosts of Toxocara canis and Toxocara cati, respectively. The high prevalence of Toxocara eggs in soil could be an evidence of dogs and cats' feces contaminating the soils. This result is also supported by the study done by Tujan and Paller, 2012 [13], which revealed that $22 \%$ of household dogs in Calamba were positive for $T$. canis. These infected dogs could be the source of parasite eggs contaminating the soil. It is also known that Toxocara can be transmitted via the placenta which increases the chance

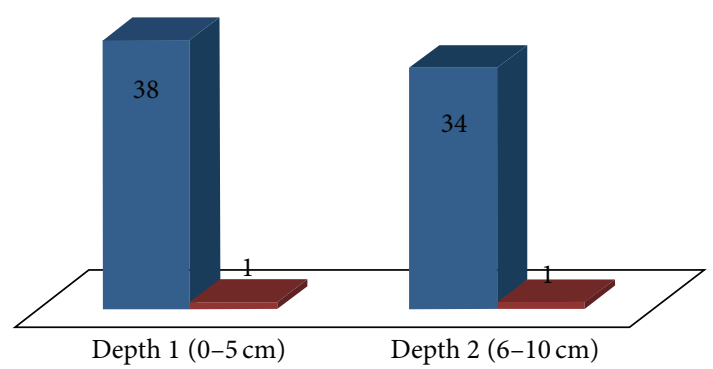

- Prevalence $(\%)$

- Mean density (eggs/g soil)

FIgURE 4: Prevalence and mean density of Toxocara eggs at different depths in soils from selected towns in Laguna, Philippines.

of pups and kittens becoming infected by Toxocara. Hence, this increases the prevalence of this helminth in dogs and cats subsequently increasing the chance of contaminating the soils through indiscriminate defecation. Toxocara is also considered as zoonotic parasite; hence, humans are vulnerable to infection. Ascaris lumbricoides, hookworms, and Trichuris trichiura are also soil-transmitted helminthes, which are infective to humans, with animals and human fecal wastes as source of soil contamination. Also, as observed, some areas of the study sites still do not have latrines or toilets, particularly in slum areas, where people may indiscriminately defecate and contaminate the soils. This condition may even be aggravated during typhoons and floods. Hence, these instances contribute to the contamination of soils with STH eggs and could contribute to their transmission.

STH infection in the Philippines has not yet been eradicated and is still prevalent. In the survey done by the department of health, 2004, 23.2\% of Filipinos examined were infected with $A$. lumbricoides. Some of these subjects were also infected with T. trichiura and hookworm due to their similar mode of transmission [14]. In addition, Fajutag and Paller [4] also revealed that $43 \%$ of public school children in Los Baños showed positive for Toxocara antigen detected through ELISA test. Thus, the high prevalence of STH eggs in soil in the study is concomitant with the high prevalence of human infection.

Prevalence of helminth eggs was also compared between urban and rural areas. Although not significant, the higher prevalence of helminth eggs in soils from urban areas may be due to high population density, which increases the possibility of soils to be contaminated with helminth eggs by animal and human wastes. The presence of stray dogs and cats that may indiscriminately defecate in the area also contributes to soil contamination with these parasites' eggs. MizgajskaWiktor and Jarosz [15] also compared prevalence of T. cati and T. canis eggs between rural and urban areas in Poland. They obtained $19.8 \%$ and $15.6 \%$ positive samples in urban and rural areas, respectively. Similar results were obtained by the study of Rai et al. [16]. Furthermore, Ascaris sp. eggs were reported to be more prevalent in soils from urban areas while hookworm larvae are more numerous in soils from rural areas [17]. 
On the other hand, the high prevalence and mean density of Toxocara eggs in empty lots may be due to lack of fences or walls which would allow infected animals to freely defecate and contaminate the soils with parasites. Schools, on the other hand, in all sampling sites were secured by tall walls or gates preventing intruders, including animals, to enter the school parameters, hence the low reported prevalence and density of STH eggs. Medina and Paller [18] had similar findings where STH eggs were most prevalent in sandy soils and least prevalent in clayey soils. Brown [10] reported that clayey soils do not provide enough oxygen needed for STH egg development. Furthermore, sandy and loamy soils are preferred by animals for defecation as they have loose texture for animals to burrow their feces deeper into the soil. Also, STH eggs survive more in sandy soils, with high silt content, since they provide aeration and moisture for their development [17-19]. Moreover, results revealed that STH eggs were also prevalent in basic soil conditions. The present study suggested that Toxocara eggs were more prevalent in conditions of high temperature and high moisture content and basic soil condition. This study revealed that soil conditions in some areas in Laguna provide optimum condition for development and embryonation of STH eggs. Soil conditions in Laguna with mean temperature (31.54 \pm $\left.2.76^{\circ} \mathrm{C}\right)$, mean moisture content $(37 \pm 6.02 \%)$, and mean $\mathrm{pH}(7.3 \pm 0.27)$ are typical tropical conditions that further allow development and transmission of the STH parasites. The result of this study is supported by the work of Lesikar et al. [8] where they identified that the optimum temperature for the embryonation of STH eggs ranges from $21^{\circ} \mathrm{C}$ to $28^{\circ} \mathrm{C}$. Hotez [19] also claimed that $20^{\circ} \mathrm{C}-30^{\circ} \mathrm{C}$ is suitable for hookworm eggs. In the study conducted by Arene [20] the most suitable temperature for Ascaris suum is between $16 \pm$ $1^{\circ} \mathrm{C}$ and $34 \pm 1^{\circ} \mathrm{C}$; as the temperature increases within this range, the development of the egg is hastened. This might be due to the effect of heat to chemical reactions occurring inside the egg for its development. Enzymes might be activated easily when there is a higher temperature and molecules come in contact more often when excited due to the energy from heat. This is also evident in the observation of Ascaris eggs in freezing temperatures, which halts development; this is mainly due to the inhibition of the chemical reactions needed for the egg development [20]. However, the development is only postponed but will continue after incubation at an optimum temperature, which means that Ascaris eggs are still viable after winter.

Moisture is needed by STH eggs to prevent desiccation or dehydration and hookworm filariform larvae especially need a moist environment since they are very sensitive to sunlight and dry condition. The moisture in the environment is also used by the hookworm larvae for moving [19]. This is related to the increased prevalence of STH eggs during the rainy season which is already observed by a number of studies [16, 21]. Moisture in soils could also provide egg with the ions needed for egg development. Some reports mentioned that helminth eggs are said to tolerate a large range of $\mathrm{pH}$. However, Ascaris suum eggs were said to have an arrested development when placed in an acidic environment. Hookworms, on the other hand, tolerate $\mathrm{pH}$ range of 4.6-9.4 and will still be able to hatch and infect [22]. According to Hotez et al. [17] Ascaris sp. eggs increase survivability by increasing soil depth. Deeper soils provide STH eggs protection from direct sunlight and provide higher moisture [11]. Thus, soil depth until $10 \mathrm{~cm}$ may still be infested with STH eggs. However, it might be interesting to examine for future studies the presence of STH eggs in depths deeper than $10 \mathrm{~cm}$.

\section{Conclusion}

The present study revealed that the contamination of soil with fecal matter is ubiquitous. In addition, the prevalence of soiltransmitted helminthes with zoonotic potential, particularly Toxocara sp. eggs, in Laguna, could be considered relatively high $(31 \%)$ and thus alarming. The zoonotic potential of Toxocara is underestimated compared to other STH parasites such as Ascaris. However, in this study, Toxocara sp. eggs showed the most prevalent STH eggs harvested from the soils and thus posing zoonotic infection risks. Local executives, therefore, should go for strict implementation of local ordinances regulating the care and custody of dogs and cats, including regular deworming of pets and other domestic animals. It is also important to emphasize to the children the importance of washing hands especially after playing with soil. As parasitic contamination in soils is a public health issue, this data should be helpful in the development of appropriate education, control, and prevention strategies of this parasitosis.

It is recommended that data will be gathered also in various parts of the country which could be subdivided into groups according to geographical location, ecological zone, socioeconomic designation, and season (wet and dry).

\section{Conflict of Interests}

The authors declare that there is no conflict of interests regarding the publication of this paper.

\section{Acknowledgments}

This work was financially supported by the University of the Philippines Los Baňos Basic Research Grant. The authors wish to thank Professor Claret B. Lauan for her assistance during the initial conduct of the experiment. Also, their appreciation is extended to the community officials of Los Baños, Bay, Calauan, and Calamba who allowed and assisted them to collect soil samples from their respective regions. Finally, this study would not have been completed without the help of Ms. Hannah Mei R. Medina and Ms. Zuriele G. Arambulo.

\section{References}

[1] M. Doligalska and K. Donskow, "Environmental contamination with helminth infective stages implicated in water and foodborne diseases," Acta Microbiologica Polonica, vol. 52, pp. 45-56, 2003. 
[2] H. Mizgajska-Wiktor and S. Uga, "Exposure and environmental contamination," in Toxocara: The Enigmatic Parasite, C. V. Holland and H. V. Smith, Eds., pp. 211-227, CABI, Cambridge, UK, 2006.

[3] J. W. Lewis, "Epidemiological surveillance of Toxocara and toxocariasis," in Toxocara: The Enigmatic Parasite, C. V. Holland and H. V. Smith, Eds., pp. 195-210, 2006.

[4] A. J. M. Fajutag and V. G. V. Paller, "Toxocara egg soil contamination and its seroprevalence among public school children in Los Baños, Laguna, Philippines," The Southeast Asian Journal of Tropical Medicine and Public Health, vol. 44, no. 4, pp. 551-560, 2013.

[5] S. Horiuchi, V. G. V. Paller, and S. Uga, "Soil contamination by parasite eggs in rural village in the Philippines," Tropical Biomedicine, vol. 30, no. 3, pp. 495-503, 2013.

[6] J. Matsuo and S. Nakashio, "Prevalence of fecal contamination in sandpits in public parks in Sapporo City, Japan," Veterinary Parasitology, vol. 128, no. 1-2, pp. 115-119, 2005.

[7] T. I. Olabiyi, A. O. Olayiwola, and G. O. Oyediran, "Influence of soil texture on distribution of phytonematodes in the South Western Virginia," World Journal of Agricultural Sciences, vol. 5, no. 5, pp. 557-560, 2009.

[8] B. Lesikar, C. Hallmark, R. Melton, and B. Harris, On-Site Wastewater Treatment Systems: Soil Particle Analysis Procedure, Agri Life Extension, Texas A and M Systems, 2005.

[9] E. Amadi and E. Uttah, "Impact of physico-chemical factors of contaminated foci on the survival of geohelminths in Abua Communities, Niger Delta Nigeria," Journal of Applied Science and Environmental Management, vol. 14, no. 4, pp. 117-121, 2010.

[10] H. W. Brown, "Studies on the rate of development and viability of the eggs of Ascaris lumbricoides and Trichuris trichiura under field conditions," The Journal of Parasitology, vol. 14, no. 1, pp. $1-72,1927$.

[11] D. W. T. Crompton, M. C. Nesheim, and Z. S. Pawlowski, "Prevalence of ascariasis," in Ascaris and Its Prevention and Control, D. W. T. Crompton, Ed., pp. 45-69, Taylor and Francis, London, UK, 1989.

[12] D. W. T. Crompton, M. C. Nesheim, Z. S. Pawlowski, and D. W. T. Crompton, "Biology of Ascaris lumbricoides," in Ascaris and Its Prevention and Control, D. W. T. Crompton, Ed., pp. 9-44, Taylor and Francis, London, UK, 1989.

[13] M. A. Tujan and V. G. V. Paller, Toxocara canis infection of household dogs in Calamba, Laguna, Philippines [unpublished undergraduate thesis], Animal Biology Division, Institute of Biological Sciences, University of the Philippines Los Banos, 2012.

[14] World Health Organization, Review of the Epidemiological Profile of Helminthiases and their Control in the Western Pacific Region, 1997-2008, World Health Organization, Geneva, Switzerland, 2008.

[15] H. Mizgajska-Wiktor and W. Jarosz, "A comparison of soil contamination with Toxocara canis and Toxocara cati eggs in rural and urban areas of Wielkopolska district in 2000-2005," Wiadomości Parazytologiczne, vol. 53, no. 3, pp. 219-225, 2007.

[16] S. K. Rai, S. Uga, K. Ono, G. Rai, and T. Matsumura, "Contamination of soil with helminth parasite eggs in Nepal," Southeast Asian Journal of Tropical Medicine and Public Health, vol. 31, no. 2, pp. 388-393, 2000.

[17] P. Hotez, N. de Silva, S. Brooker, and J. Bethony, "Soil transmitted helminth infections: the nature, causes and the burden of the condition," Disease Control Priorities Project Working
Paper 3, Fogarty International center, National Institute of Heath, Bethesda, Md, USA, 2003, http://www.dcp2.org/file/19/ wp3.pdf.

[18] H. Medina and V. G. V. Paller, Soil-transmitted helminth eggs collected from Bay and Los Baños Laguna and some environmental factors affecting their prevalence [Undergraduate thesis], Animal Biology Division, Institute of Biological Sciences, University of the Philippines Los Banos, 2011.

[19] P. J. Hotez, "Hookworm and poverty," Annals of the New York Academy of Sciences, vol. 1136, pp. 38-44, 2008.

[20] F. O. I. Arene, "Ascaris suum: influence of embryonation temperature on the viability of the infective larva," Journal of Thermal Biology, vol. 11, no. 1, pp. 9-15, 1986.

[21] S. Uga, K. Ono, N. Kataoka et al., "Contamination of soil with parasite eggs in Surabaya, Indonesia," The Southeast Asian Journal of Tropical Medical and Public Health, vol. 26, no. 4, pp. 730-734, 1995.

[22] World Health Organization, Integrated Guide to Sanitary Parasitology, WHO Regional Office for the Eastern Mediterranean, 2004. 

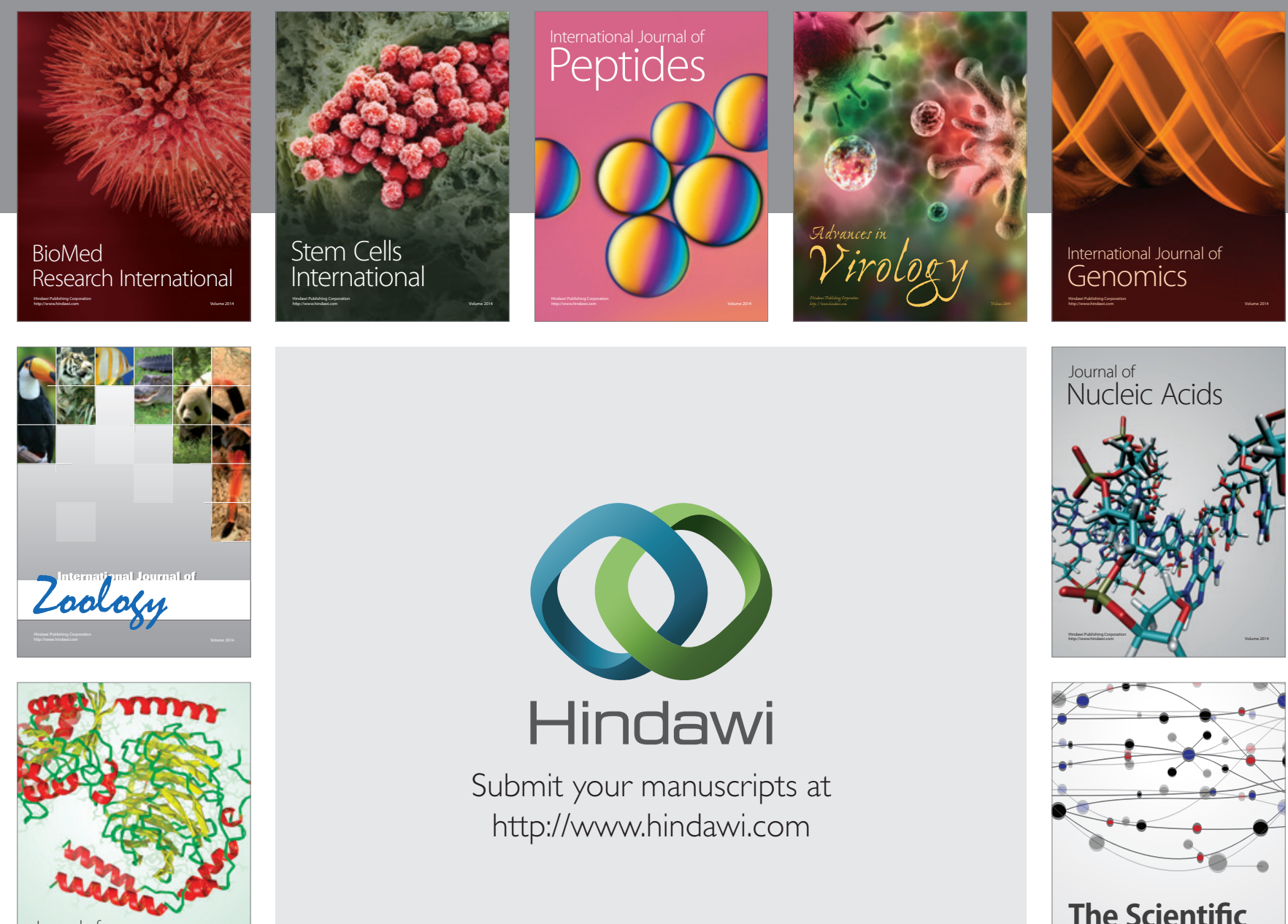

Submit your manuscripts at

http://www.hindawi.com

Journal of
Signal Transduction
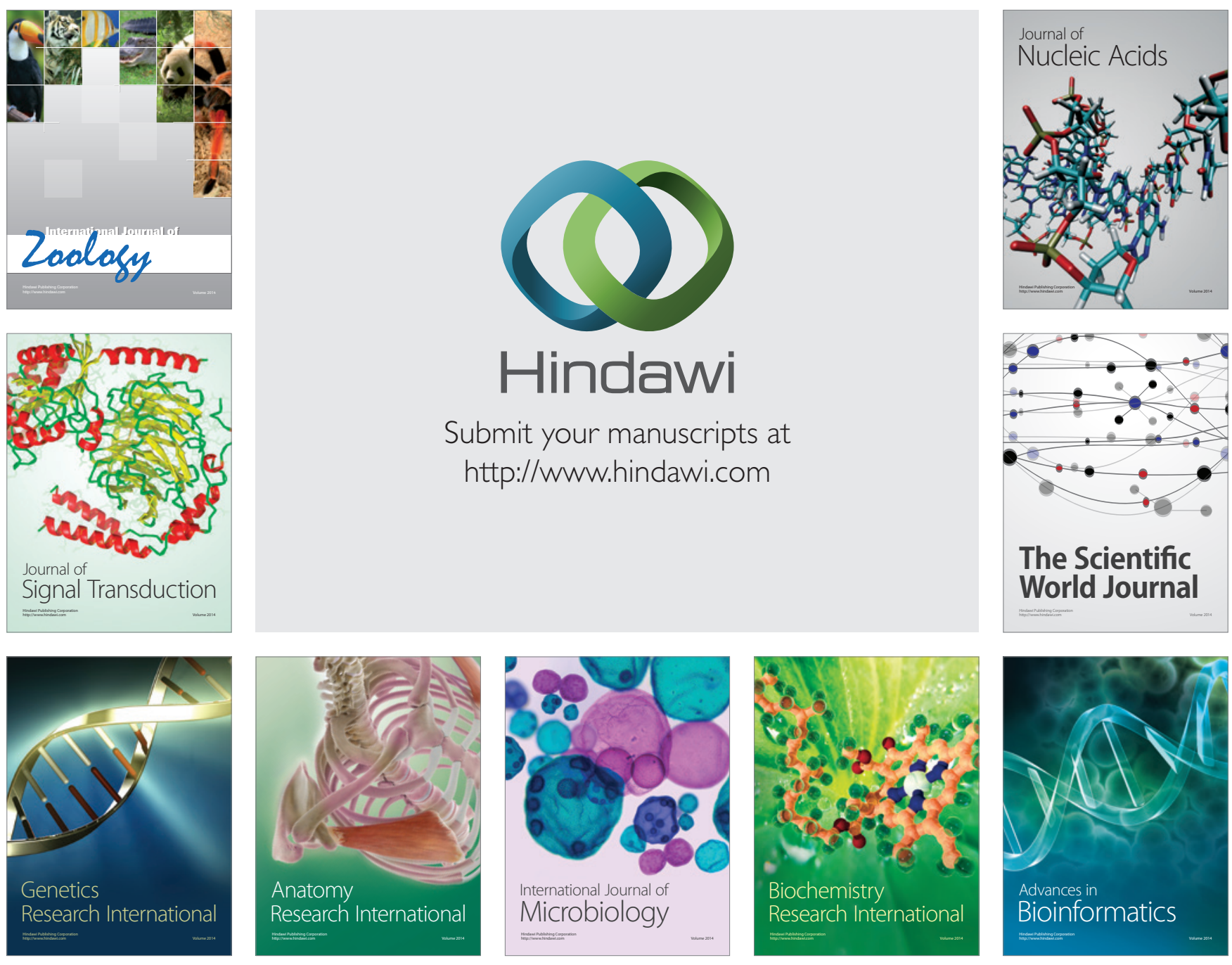

The Scientific World Journal
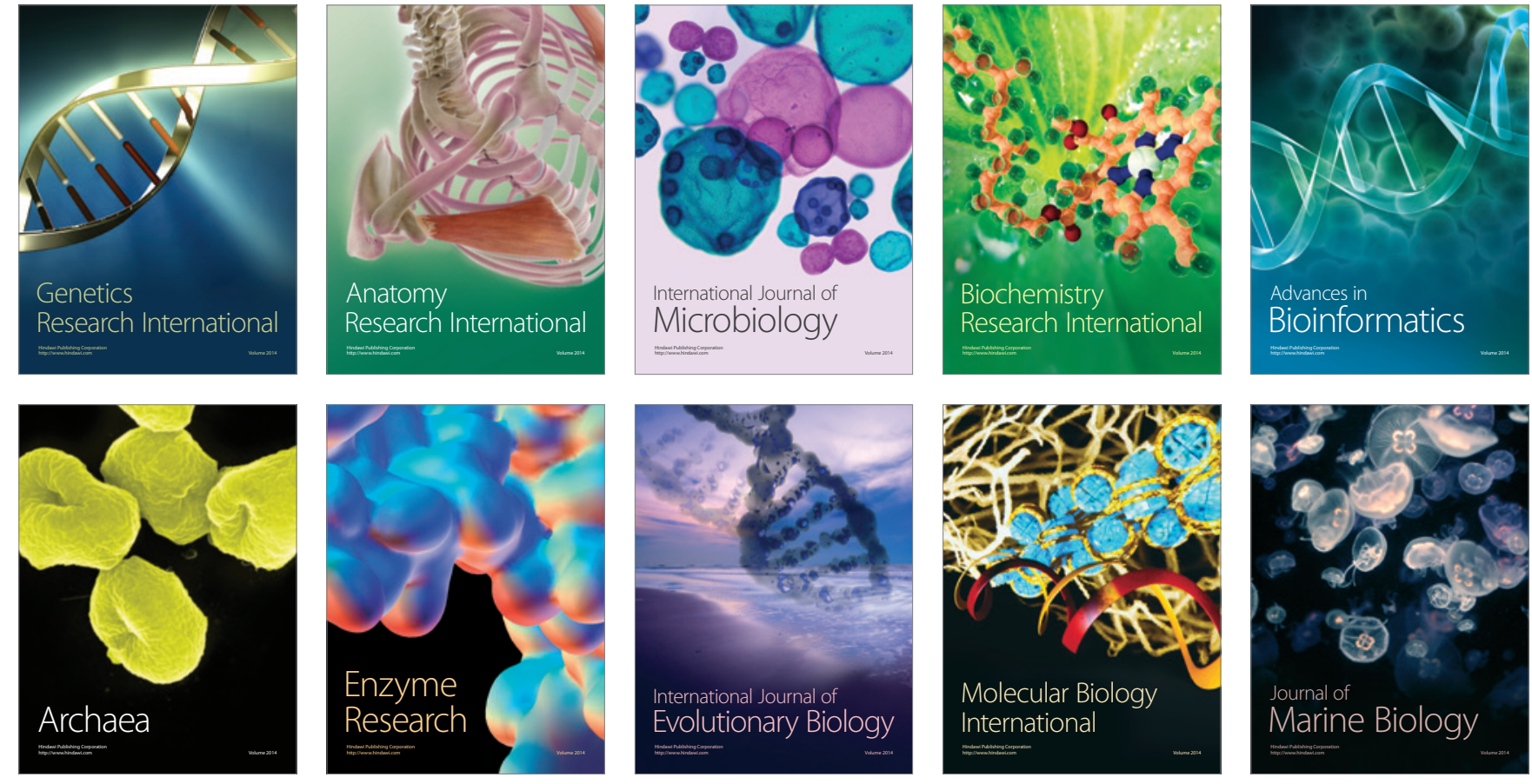